\title{
PERCEPÇÃO DOS PROFESSORES SOBRE O ENSINO REMOTO EMERGENCIAL DURANTE A PANDEMIA DA COVID-19, NA VILA DE CARAPAJÓ/CAMETÁ, PARÁ
}

\author{
Lays do Carmo Cavalcante Trindade (iD); Lorena Fonseca do Carmo iD2; Bruno \\ Andrade da Silva 3
}

Resumo: Com a pandemia da COVID-19 espalhada pelo mundo, medidas de contenção foram impostadas pelas autoridades governamentais, que fizeram com que uma nova situação fosse colocada diante da realidade escolar. Professores e alunos ficaram cada vez mais distantes fisicamente e conectados por meio de um único recurso possível, a tecnologia. Este trabalho apresenta como tema o Ensino Remoto Emergencial (ERE) e tem como objetivo compreender a percepção dos professores sobre o ERE, tendo como abordagem um pesquisa exploratória que teve como procedimentos a coleta de dados acerca das opiniões dos professores de uma escola pública localizada no interior do estado do Pará, sobre a utilização das Tecnologias Digitais de Informação e Comunicação (TDIC) no Ensino Remoto Emergencial (ERE) durante a pandemia. Foram aplicados questionários e realizado entrevistas a 23 professores. Durante o estudo foi observado que a maioria dos professores permaneceram ministrando aulas de maneira remota e disponibilizando materiais para seus alunos. Contudo, observou-se que não foi ofertado curso de capacitação para a utilização de recursos tecnológicos aos professores. Identificamos também limitações de acesso à internet e aos equipamentos eletrônicos por parte de alguns alunos. Por essas razões, a maioria $(65,2 \%)$ dos professores relataram que o ERE tem caráter intermediário, colocando-o como mais um desafio em sua formação continuada nas escolas públicas brasileiras.

Palavras-chave: Ensino Remoto Emergencial; Tecnologia de Informação e Comunicação; Desafios; Docente.

\section{TEACHERS' PERCEPTION ON THE EMERGENCY REMOTE EDUCATION DURING THE COVID-19 PANDEMIC IN CARAPAJÓ VILLAGE IN THE CITY OF CAMETÁ, PARÁ STATE}

Abstract: With the spread of the COVID-19 pandemic throughout the world, containment measures were imposed by government authorities, which caused a challenge to be posed before the school reality. Teachers and students have become increasingly physically distant, but connected through a single possible resource, technology. This paper entitled "The Emergency Remote Teaching (ERT)"

\footnotetext{
${ }^{1}$ Especialista em Informática Educativa pelo Instituto Federal do Pará (IFPA). E-mail: laiscavalcante47@gmail.com.

${ }^{2}$ Especialista em Informática Educativa pelo Instituto Federal do Pará (IFPA). E-mail: lorenacarmo64@gmail.com

${ }^{3}$ Mestre em Informática Aplicada pela da Universidade de Fortaleza (Unifor-CE). Professor do Ensino Básico, Técnico e Tecnológico (EBTT) do Instituto Federal de Educação, Ciência e Tecnologia do Pará (IFPA), Campus de Cametá. E-mail: bruno.andrade@ifpa.edu.br.
} 
aims to understand the teachers' perception on the ERT, and has as an approach the explanatory research which had as procedures the data collected on the teachers' opinions of a public school in the countryside of Pará State on the use of Digital Information and Communication Technology (DICT) in Emergency Remote Teaching (ERT) during the pandemic. Questionnaires were applied and interviews were held with 23 teachers. During the study, it was observed that the majority of teachers kept on teaching remotely and making didactic materials available to their students. Furthermore, training courses on the use of technological resources were not offered for most of them. It was also observed that the students have restricted access to the Internet and electronic equipment. Given these points, the majority $(65.2 \%)$ of teachers reported that the ERT has an intermediate character, thus, considering it as one more challenge in their continuing education in Brazilian public schools.

Keywords: Emergency Remote Teaching; Information and Communication Technology; Challenges. Teacher.

\section{Introdução}

Ultimamente o Brasil e o mundo vêm tendo grandes dificuldades em razão da crise sanitária ocasionada pelo Covid-19, doença causada pelo novo coronavírus (Sars-Cov-2). Inúmeras são as formas de contaminação pelo vírus, que apresenta elevada taxa de transmissão e um grande percentual de letalidade. As principais medidas para frear a disseminação do vírus são o uso de máscara, a higienização de objetos individuais e das mãos, 0 isolamento social e a quarentena. $O$ isolamento social e a quarentena trouxeram inúmeras modificações em nosso cotidiano e gerou rápidas transformações sociais, o que nos forçou a desacelerar nossa vida e o que nos fez repensar nas nossas relações de trabalho, estudo e lazer. Diversos setores tiveram que fechar as portas, com a educação não poderia ser diferente, ocasionando o afastamento de docentes e discentes.

A suspensão das atividades escolares presenciais, impactou em cerca de mais 44 milhões de estudantes da educação básica do Brasil (UNESCO, 2020) e foi decretado por meio da Portaria no 343, de 17 de março de 2020, publicada em caráter excepcional, sendo substituídas por aulas online, que utilizem meios e Tecnologias Digitais de Informação e Comunicação (TDIC), nos limites estabelecidos pela legislação em vigor (BRASIL, 2020b). A suspensão das aulas presencias é uma das medidas essenciais para evitar a propagação da contaminação, haja visto que a sala de aula é uma grande rede de interações sociais, e, para que essa organização funcione como instrumento de aprendizagem, é muito importante que haja uma boa comunicação entre o professor e os alunos; pais e alunos; professor e pais; aluno e alunos (DAYRELL, 1999 p. 137).

Com o encerramento das aulas presencias e a pandemia se alastrando rapidamente não havendo tempo para grandes planos, autoridades, gestores e professores entraram em consenso que a educação escolar não poderia parar, com o objetivo de os alunos não perderem o ano letivo. Surge, então a necessidade da adaptação e superação no modo de ensinar e aprender por parte de alunos e 
professores, descrito, por Gomes et al. (2020), como "ensino remoto emergencial". Nascimento (2020) corrobora que o Ensino Remoto Emergencial (ERE), que é um modelo de educação que fora concebido para que se adapte o ensino a fim de reduzir os impactos a um nível minimamente aceitável. A decisão por aulas remotas foi a mais acertada e tornou-se a principal alternativa para as instituições educacionais de todos os níveis de ensino.

As inúmeras mudanças no sistema educacional brasileiro, tiveram que ser feitas rapidamente. Professores precisaram adaptar seus conteúdos impressos e aulas presencias para ferramentas online com a ajuda das TDIC disponíveis, tornando-se fundamental no dia a dia dos professores. Conforme afirmam (SANCHOTENE et al., 2020, p.2):

a presença das Tecnologias Digitais da Informação e Comunicação (TDIC) no ensino remoto, em consequência ao isolamento social, tornou-se indispensável no nosso dia a dia e tem alterado visivelmente os meios de comunicação e a maneira como nos comunicamos.

A utilização das TDIC no ensino remoto de fato tem beneficiado os professores na nova maneira de ministrar aula, porém para haver de fato esse benefício os professores precisaram desenvolver as habilidades e competências necessárias para mediar processo de ensino-aprendizagem a partir das TDIC. De acordo com (FERRARI, 2012):

as competências digitais docentes estão relacionadas a um conjunto de conhecimentos, habilidades, atitudes e estratégias que possibilite a realização de diferentes atividades socialmente valorizadas com uso das TDIC, tais como a resolução de problemas, gerenciamento da informação, colaboração, criação e compartilhamento de conteúdo.

A realidade dos dias atuais traz novos desafios para os docentes na construção do processo de ensino e aprendizagem em aulas remotas, por tratarse de uma experiência relativamente nova e repentina, porém tendo como aliado principal a tecnologia. Conforme diz, (FRANÇA, 2020) "o professor precisou se apropriar e dominar essas tecnologias para poder ensinar remotamente seu aluno". Sob esse aspecto, justifica-se o desenvolvimento desta pesquisa a respeito dos conhecimentos digitais dos docentes e o uso das TDIC na Educação Básica, durante o ensino emergencial, na pandemia do COVID-19, visto que, as informações sobre o desenvolvimento da qualificação digital dos docentes e o impacto no processo educacional poderão conceder recursos para auxiliar na sua formação.

Para tanto, o presente estudo tem por objetivo mostrar dados coletados acerca das opiniões dos professores de uma escola pública localizada no interior do estado do Pará, sobre a utilização das TDIC nas aulas remotas durante a pandemia da COVID-19. Além mostrar quais as plataformas utilizadas para ministrar as aulas, bem como saber se de fato as aulas remotas contribuíram para auxiliar na sua formação inicial e contínua.

\section{Metodologia}


O presente trabalho buscou compreender à opinião dos professores sobre o ensino remoto emergencial durante a pandemia do COVID-19 e quais foram as tecnologias utilizadas para ministrar suas as aulas. Á vista disso, utilizou-se uma pesquisa exploratória com a finalidade de averiguar e relatar os dados coletados, a pesquisa ocorreu forma presencial (aplicação de questionários impresso na forma de entrevistas) e virtual (através de Google Forms). Este último recurso devido questões de segurança e bem-estar dos participantes.

No que diz respeito à natureza dos dados, fez-se uso de uma abordagem quantitativa com o intuito de coletar informações através de questionário impresso e virtual (Google forms), envolvendo perguntas sobre a continuidade, plataformas e formato das aulas, acesso à internet, tipos de atividades realizadas no ensino remoto, os desafios encontrados pelos professores na preparação de aulas através do ensino remoto e recursos tecnológicos utilizados. De acordo (DINIZ et al.,2020) as perguntas elaboradas para esse questionário objetivaram desvelar os significados que o professor vem construindo, ao longo do desenvolvimento das aulas remotas emergenciais, sobre o processo de ensinar e aprender neste contexto específico.

A escola na qual se realizou a pesquisa foi definida pela proximidade com a casa dos pesquisadores, pelo fato da pesquisadora ter sido aluna da escola e por fim pela receptividade da Gestão da mesma. Trata-se de uma escola estadual localizada no interior do município de Cametá, vila do Carapajó, interior do Estado do Pará (PA). A escola possui 26 professores da educação básica (Ensino Fundamental) relacionados em seu quadro docente, dos quais 23 responderam/participaram desta pesquisa, o que equivale a $88,46 \%$ do total de professores. O critério para participação nesse estudo foi estarem atuando, no período da pesquisa, com o ERE.

O questionário foi disponibilizado de forma impressa, deixado na escola com a diretora, para a mesma repassar aos professores e também em formato online elaborado no Google Forms e entregue através do aplicativo WhatsApp, por meio do compartilhamento do link. Estabeleceu-se um período para a devolutiva de nosso instrumento de coleta de dados.

Importa ressaltar que alguns professores (13) aceitaram realizar a pesquisa de forma presencial em formato de entrevista. Desta forma, obteve-se dados qualitativos uma vez que o professor após indicar sua resposta no questionário, acrescentava de forma espontânea suas particularidades e observações sobre o ERE. Sendo assim, após o recebimento do questionário devidamente respondido e análise das entrevistas, procedeu-se à organização dos dados.

Para o tratamento das informações obtidas, foram relatados de maneira discursiva e organizados em gráficos que ajudaram na leitura das questões e possibilitaram a materialização, através das opiniões dos professores sobre a utilização das TDIC nas aulas remotas emergências.

\section{Resultados e discussões}

A existência da pandemia da COVID-19 que atingiu todos os países, nos levou inúmeras modificações e adaptações. De acordo com (DINIZ et al., 2020), os impactos ocasionados na sociedade são de variadas ordens, que vão desde à 
economia do país, passando por questões sociais, culturais, históricas do povo brasileiro, até aos aspectos envolvidos na educação escolar. Neste último, professores e alunos tiveram que permanecer distantes fisicamente, sendo assim foi necessário contar com auxílio da tecnologia, para que o ensino de certa forma, na medida do possível, não sofresse tanto impacto.

Nesse contexto, participaram do estudo relatando suas experiências com ERE, 23 (vinte e três) professores do ensino fundamental. Para tanto, apresentamos as questões que foram elaboradas no questionário. A primeira versa sobre a área de formação do professor; a segunda se o mesmo tem ministrado aula durante a pandemia da COVID-19; a terceira se foi ofertado cursos de capacitação para utilização de recursos tecnológicos e aulas remotas; a quarta refere-se quais dispositivos tecnológicos são utilizados para ministrar aula no ensino remoto emergencial; a quinta sobre aonde os professores utilizam esses recursos (se utilizam em suas casas ou na escola); a sexta sobre se houve dificuldade na utilização dos recursos tecnológicos; a sétima sobre quais as plataformas os professores utilizaram para ministrar as aulas remotas ; a oitava se os professores utilizam alguma rede social para acompanhar o desenvolvimento de seus alunos; a nona se os professores disponibilizam materiais de apoio para seus alunos durante as aulas remotas; a décima sobre a opinião dos professores sobre o ensino remoto.

Em relação área de formação dos professores, os dados mostram que nenhum participante possui Magistério Médio. Assim, obteve-se que 47,8\% de professores com formação em Pedagogia, 8,7\% dos docentes participantes são formados em Matemática; 4,3\% em Educação Física; com habilitação em Letras/Língua Portuguesa são $8,7 \%$ dos professores; já com Licenciatura em História são 4,3\%; e na mesma porcentagem, de 4,3\%, são os professores licenciados em Geografia; Letras com Habilitação em Língua Inglesa; Ensino de Ciências; Estudos Amazônicos; Ensino Religioso e Artes. Desse modo, reafirma-se o que se observa no Censo do professor de 2007, no qual expõe-se o crescente número de profissionais que vêm se formando em graduações (BRASIL, 2009).

Os entrevistados responderam ainda sobre se estavam ministrando suas aulas durante a pandemia da COVID-19. Foi observado que 56,5\% dos professores estavam ministrando aulas online e presencial, o modo presencial relatado pelos professores, são os dias em que precisam ir até a escola para entregar as atividades escolares. Informaram-nos que 34,8\% estavam ministrando aulas somente de maneira online e nenhum professor relatou estar lecionando de maneira somente presencial e $8,7 \%$ dos entrevistados nos informaram que não estavam ministrando aula durante a pandemia, pois disseram não contar como aulas essa maneira remota de ensinar. Tal afirmação despertou curiosidade e através de uma pesquisa pontual: entrevista, identificamos que os professores que afirmaram não contar como aulas o ensino remoto é porque estes, entendem que o aluno não irá absorver o mínimo de conteúdo necessário para seu processo de aprendizagem, seja por obstáculos técnicos: internet, equipamentos, seja pela questão de que muitos não estão familiarizados com a dinâmica do autoestudo, onde o aluno deve buscar o protagonismo de seu aprendizado. Percebeu-se que existe conteúdo a ser explorado em outra pesquisa onde as perguntas sejam 
abertas para melhor compreensão da visão dos professores desta escola sobre o ERE.

Quando questionamos se o professor recebeu algum curso/treinamento para realizar suas atividades remotas, $78,3 \%$ deles responderam que não e $21,7 \%$ diz que sim. Esses dados destacam a importância de formação continuada, e o despreparo dos sistemas para oferecer possibilidades de trabalho, bem com o suporte necessário. Alguns docentes relataram que buscou orientações fora do âmbito escolar para melhorar o seu trabalho com as tecnologias digitais, já que não foi ofertado esse suporte pelos órgãos competentes. Essa informação é bastante relevante e precária, pois indica que o professor foi levado a buscar outras alternativas para desenvolver conhecimentos e habilidades essenciais para atuar no cenário de aulas remotas emergenciais. Entende-se que o professor não é o único agente responsável pela sua formação, faz-se necessário um planejamento das Instituições de Ensino para que a responsabilidade por um eventual insucesso não seja meramente apontada apenas ao professor.

Dentre os dispositivos utilizados nas aulas remotas, durante o período pandêmico, para realizar atividades relacionadas ao trabalho escolar $52,2 \%$ dos docentes utilizam o smartphone, 34,8\% o notebook, $13 \%$ o computador e nenhum professor mencionou usar tablet nas suas aulas remotas, conforme exemplificado na (Figura 1).

\section{Gráfico 1: Dispositivos mais utilizados pelos professores para dar aulas no ERE.}

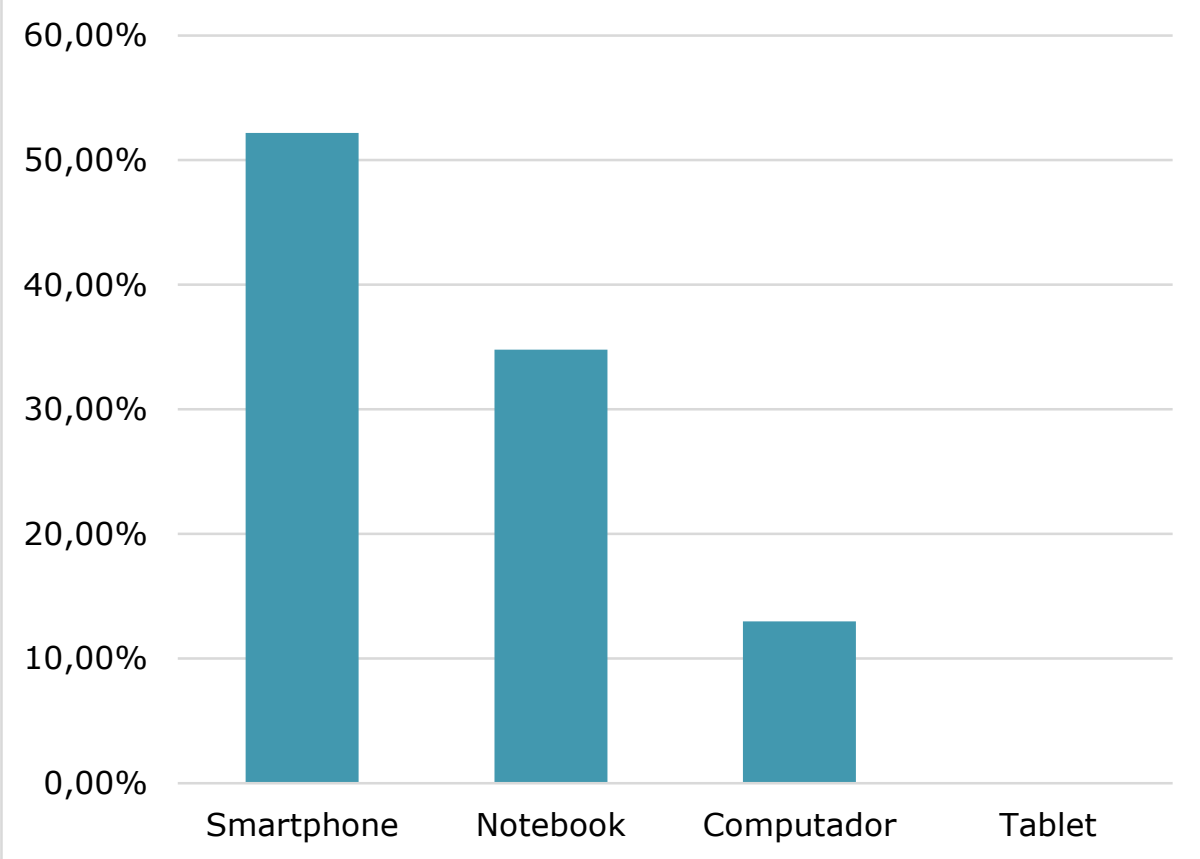

Fonte: Elaborado pelos autores (2020).

Para preparar seus materiais e planejar momentos de conferência ao vivo, $87 \%$ dos professores responderam que fizeram utilização dos recursos tecnológicos em casa, $13 \%$ relatou que utilizam na escola e nenhum docente disse que fazem uso em casas de seus conhecidos ou parentes. Alves (2020) reafirma que o ensino remoto se caracteriza como um recurso ou estratégia de ensino, onde 
são utilizados meios de comunicação ou tecnologia da informação com o objetivo de viabilizar as atividades realizadas fora do ambiente escolar. Entre esses professores entrevistados, $65,2 \%$ dos docentes relataram que não tiveram dificuldades na utilização dos recursos tecnológicos, pois buscaram pesquisar sobre ou já usavam algum tipo de tecnologia digital para uso pessoal antes da pandemia da COVID-19. Importa ressaltar que a maioria das licenciaturas estão bem conectadas com as tecnologias educacionais, estimulando sua aplicação em sala de aula e discutindo suas teorias e paradigmas, através de disciplinas especificas, seminário e ações de pesquisa e/ou extensão. Entretanto, temos um percentual de $34,8 \%$ de docentes que afirmaram que tiveram dificuldades na utilização de alguma tecnologia digital. Os que relataram dificuldades, informaram que era um cenário de novidades e que a tecnologia não fazia parte do cotidiano, e isso é bastante preocupante, se considerarmos que vivemos no contexto da cultura digital. Os docentes relataram ainda que em meio as dificuldades encontradas, estavam presentes o acesso à internet e a falta de equipamentos tanto por parte deles como principalmente por partes dos alunos.

Esta falta de equipamento é um problema sério, visto que, o ERE deveria ser para $100 \%$ dos alunos, logo, se existem relatos da falta de equipamento seja para professores, seja para alunos significa que estes não atingiram as metas estabelecidas para o processo de ensino aprendizagem, ocasionando uma responsabilização errada a cerca destes agentes.

Conforme, (DUARTE et al., 2020) em tempos de "ensino remoto" acreditase ser possível continuar desenvolvendo do processo educacional com o apoio das tecnologias como alternativa para não suspender as aulas. Dessa maneira aulas remotas estão sendo conduzidas, particularmente por meio de ferramentas e recursos online e gratuitos. Perguntamos aos entrevistados, se estão fazendo uso de alguma plataforma para ministrar as aulas. Os professores informaram que $47,8 \%$ não faz uso de nenhuma plataforma de ensino, pois relataram "fiz a utilização do Google Meet no início do processo, depois não fiz mas, por conta da péssima qualidade da internet". Por outro lado, tivemos $21,7 \%$ dos professores que relataram fizeram utilização do Google Meet. De acordo com, (DUARTE et al., 2020) o Google Meet constitui um exemplo de aulas remotas em ferramentas síncronas, as aulas acontecem com horário marcado via transmissão em tempo real. $4,3 \%$ os entrevistados fazem utilização da plataforma Gestor, elaborada pela secretaria de ensino do município, para a utilização de professores e direção das escolas. O WhatsApp também foi citado como uma das principais ferramentas por $26,2 \%$ dos entrevistados, devido à familiaridade e facilidade de acesso, tornandose uma ferramenta de diálogo entre os sujeitos. Nenhum entrevistado mencionou fazer uso das ferramentas Zoom e Google Class Room, nas aulas remotas.

Perguntamos também se o professor faz uso de alguma rede social para fazer acompanhamento ou desenvolvimento educacional de seus alunos. Entre os professores $100 \%$ relataram a utilização WhatsApp, foi unanime a escolha dessa rede social entre os entrevistados, acredita-se por ser fácil de utilizar e obter uma resposta quase que imediata de seus alunos. Nenhum professor mencionou fazer uso de outra rede sociais com Facebook, Instagram e Twitter. No que se refere ao retorno das atividades enviadas para os estudantes, $82,6 \%$ são devolvidas através de material impresso e outra plataforma virtual, $17,4 \%$ entregam materiais para 
seus alunos apenas de maneira impressa, pois os mesmos relatam não terem familiaridade com tecnologia. Nenhum entrevistado respondeu se disponibiliza apenas de maneira virtual e também não responderam quem não encaminha as atividades. Dessa maneira pode-se concluir que seja de maneira impressa ou virtual, os alunos estavam recebendo atividades.

Por fim, foi perguntado aos docentes, o que os mesmos achavam do ensino remoto em geral, $8,7 \%$ dos entrevistados consideram o ensino remoto bom, $26,1 \%$ consideram ruim e $65,2 \%$ relatou que o ensino remoto é mediano. $\mathrm{E}$ nenhum entrevistado relatou achar o ensino remoto excelente. Conforme a (figura 2) mostra.

\section{Gráfico 2: Opinião dos docentes sobre o ERE na pandemia da COVID-19.}

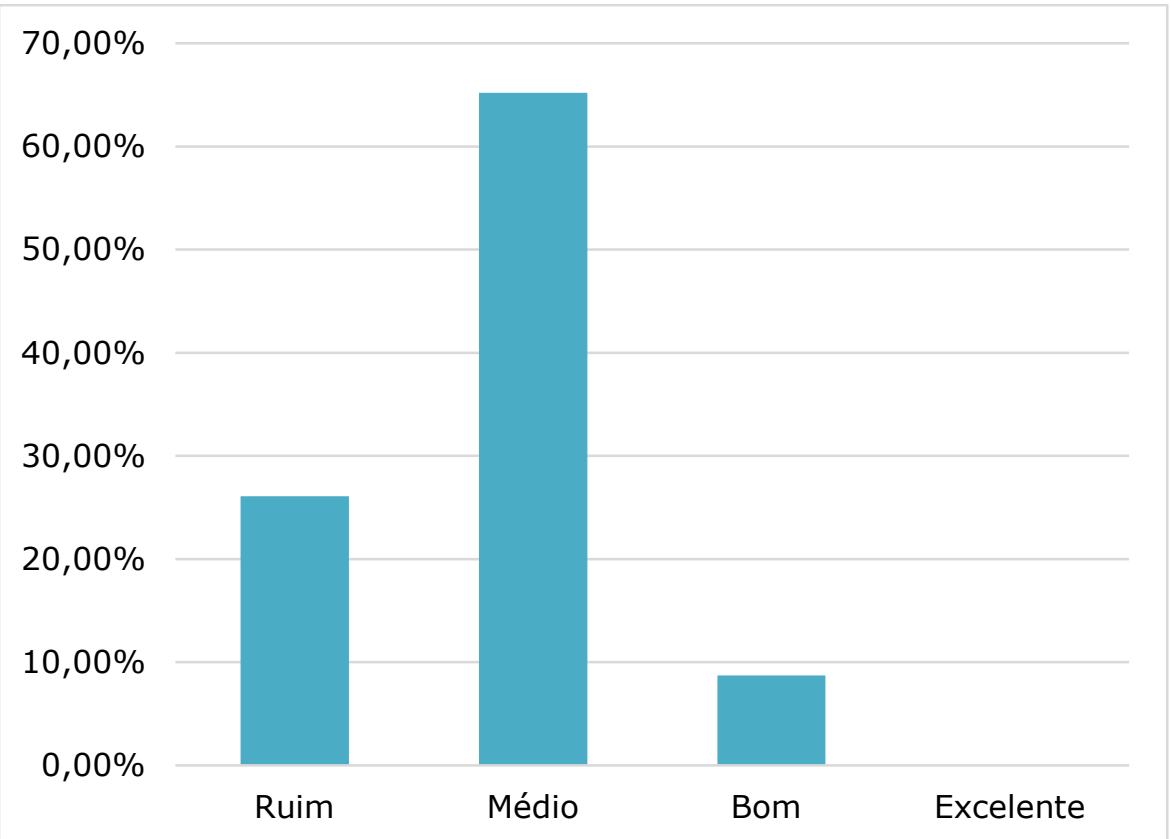

Fonte: Elaborado pelos autores (2020).

A respeito da opinião dos professores sobre o ensino remoto emergencial, alguns professores relataram que "o real problema foi a falta de acesso dos alunos à internet e do aparelho celular, a falta de conhecimento básico de informática tanto para os alunos quanto para alguns professores". Também mencionaram "a necessidade de treinamentos/cursos de capacitação para a utilização das tecnologias para a produção de materiais, pois só estávamos acostumados da maneira tradicional que era mediante a utilização do quadro branco". Conforme (LEITE et al.,2020), esses dados ressaltam que a falta de equipamentos, acesso à internet, formação dos docentes e estruturas são pontos cruciais para se realizar um ensino remoto emergencial proposto pelos sistemas de ensino.

\section{Considerações finais}

A pandemia ocasionada pelo novo Coronavírus acarreta efeitos e modificações imensuráveis na educação. Docentes de vários países do mundo tiveram que enfrentar uma nova realidade, modificar sua maneira de ministrar 
aulas, desenvolver habilidades, criatividades e competências para o ensino remoto, pautadas na nova maneira de comunicação entre alunos e professores por meio do uso TDIC na educação. O uso das tecnologias digitais, estão em nosso convívio há vários anos, principalmente entre os jovens e adolescentes, todavia a sua presença e o financiamento na educação eram relativamente baixos. Com a pandemia do COVID-19, a maneira tradicional de ensinar foi modificada e teve que ser deixada de lado pelo distanciamento social, adaptando-se rapidamente ao ERE.

Diante do cenário pandêmico, o artigo traz ponderações e resultados alcançados através de um instrumento de pesquisa que objetiva mostrar dados coletados acerca das opiniões dos professores de uma escola pública localizada no interior do estado do Pará, sobre a utilização das TDIC nas aulas remotas durante a pandemia. É relevante frisar que o período da pesquisa equivale ao momento novo experimentado pelos docentes, em decorrências do estado de calamidade pública submetida pela pandemia.

Mediante aos dados atingidos do presente estudo, pode-se compreender que não foram ofertados cursos/treinamentos sobre a utilização de recursos tecnológicos para aulas remotas para a grande maioria dos professores. Portanto, os docentes tiveram que buscar orientações sobre do âmbito escolar para melhorar seu trabalho e consequentemente oferecer um ensino qualificado aos seus alunos. Sobre os dispositivos, os mais utilizados pelos professoras nas remotas, foi o smartphone, por ser aquele a que estavam mais habituados e disponível em seu cotidiano. No que tange ao desenvolvimento das aulas, poucos foram os professores que conseguiram ministrá-las através de plataformas de ensino, com o Google Meet. O recurso mais utilizado no processo de ensino-aprendizagem foi o material impresso e o aplicativo WhatsApp, sendo a rede social optada pelos professores para acompanhar o desempenho de seus alunos. É de extrema importância frisar que para grande maioria dos professores o ensino remoto emergencial está sendo considerado intermediário, pois ainda há muito o que ser feito.

Dessa maneira, muitas lições já foram tiradas do processo. Os problemas enfrentados pela escola continuam, da mesma forma, só que no momento de modo remoto. Outras lições ainda iremos aprender. Para os docentes, a comprovação principal é que ele necessita sempre se reinventar. Para os discentes, que eles precisam continuar seus estudos, mesma que seja em um formato que antes era considerado desconhecido. A escola, por último, comprova e adere estratégias pedagógicas jamais imaginadas. Dessa forma consegue planejar e adaptar-se. Alunos e professores reconhecem a relevância da presença. Assim que a situação permitir, todos vão voltar à escola, vivenciando novos desafios e conquistadas, sem jamais esquecer o tempo em que estamos vivendo. Assim iremos manter o que faz sentido e transformar o que for necessário.

\section{REFERÊNCIAS}

ALVES, Marly Gomes da Silva. Vivências lúdicas na educação infantil e o contexto de pandemia de covid-19 no Brasil (2020). 2020. 62f. Trabalho de Conclusão de Curso - Universidade Federal da Paraíba (UFPB), Duas Estradas, Paraíba. 
BRASIL. Diário Oficial da União. Portaria no 343, de 17 de março de 2020. 2020b. Disponível em: https://abmes.org.br/arquivos/legislacoes/Portaria-mec343-2020-03-17. Acesso em: 11 mar. 2021.

BRASIL. Ministério da Educação. Instituto Nacional de Estudos e Pesquisas Educacionais Anísio Teixeira (INEP). Estudo exploratório sobre o professor brasileiro com base nos resultados do Censo Escolar da Educação Básica 2007. Brasília: INEP, 2009. 63 p. Disponível em:

http://portal.mec.gov.br/dmdocuments/estudoprofessor.pdf. Acesso em: 27 mar. 2021.

DAYRELL, Juarez. (Org.). Múltiplos olhares sobre educação e cultura. Belo Horizonte: Editora da UFMG, 1999.

DINIZ, Lara Thayná da Silva; PADILHA, Yasmim de Lima; SOUSA, Ana Edilza Aquino de; MEDEIROS, Joseane Maria Araújo de; SOUZA, Priscila Daniele Fernandes Bezerra. Percepção de professores sobre o processo de ensino e aprendizagem em tempos de pandemia. In: CONEDU: VII CONGRESSO NACIONAL DE EDUCAÇÃO, 7., 2020, Maceió. Disponível em: https://editorarealize.com.br/index.php/artigo/visualizar/68292 Acesso em: 27 mar. 2021.

DUARTE, Kamille Araújo; MEDEIROS, Laiana da Silva. Desafios dos docentes: as dificuldades da mediação pedagógica no ensino remoto emergencial. In: CONEDU: VII CONGRESSO NACIONAL DE EDUCAÇÃO, 7., 2020, Maceió. Disponível em: https://editorarealize.com.br/index.php/artigo/visualizar/69274 Acesso em: 11 mar. 2021.

FERRARI, Anusca. Digital competence in practice na analysis of Frameworks. Sevilla: JRC Spain: Institute for Prospective Technological Studies. European Commission. IPTS, ISBN 978-92-79-25093-4. Disponível em: https://bit.ly/3gVMdcL. Acesso em: 29 abr. 2021.

FRANÇA, Adriano. Como os professores das escolas públicas estão lidando com as aulas remotas frente à pandemia. In: III SENPRE: SEMINÁRIO NACIONAL DE PESQUISA EM EDUCAÇÃO, v. 3, n.1, 2020. Disponível em:

https://portaleventos.uffs.edu.br/index.php/SENPE/article/view/14940 Acesso em: 27 mar. 2021.

GOMES, Vânia Thais Silva; RODRIGUES, Roberto Oliveira; GOMES, Raimundo Nonato Silva; GOMES, Maria Silva; VIANA, Larissa Vanessa Machado; SILVA, Felipe Santana e. A Pandemia da COVID-19: Repercussões do Ensino Remoto na Formação Médica. SCIELO. Brasília, v. 44, n.4. Disponível em: https://doi.org/10.1590/1981-5271v44.4-20200258. Acesso em: 25 de abr. 2021. 
LEITE, Nahara Morais; LIMA, Elidiene Gomes Oliveira de; CARVALHO, Ana Beatriz Gomes. Os professores e o uso de tecnologias digitais nas aulas remotas emergenciais, no contexto da pandemia da COVID-19 em Pernambuco. Em Teia - Revista de Educação Matemática e Tecnologia Iberoamericana da UFPE, Recife. v.11, n.2, p.1-15, 2020. Disponível em:

https://periodicos.ufpe.br/revistas/emteia/article/view/248154 Acesso em: 25 de abr. 2021.

NASCIMENTO, Belmiro José da Cunda. A construção de um novo paradigma de educar: do singular ao coletivo, reflexões necessárias em tempos de pandemia. Sumários de Revistas Brasileiras.org - Universidade Federal do Espirito Santo/UFES. Simbiótica, Edição Especial, Vitória, vol.7, n.1, p. 127-146, 2020. Disponível em: https://periodicos.ufes.br/simbiotica/article/view/30987 Acesso em: 25 de abr. 2021.

SANCHONETE, Ismael Jung; ILHA, Phillip Vilanova; RUPPENTHAL, Raquel; ENGERS, Patrícia Becker. Competências Digitais Docentes e o Processo de Ensino Remoto Durante a Pandemia de Covid-19. Em Foco - Revista Científica em Educação a Distância. v.10, n.3, p.1-11. 2020. Disponível em: https://eademfoco.cecierj.edu.br/index.php/Revista/article/view/1303 Acesso em: 25 de abr. 2021.

UNESCO. Impacto da COVID-19 na educação. 2020. Disponível em: http://pt.unesco.org/covid19/educationreponse. Acesso em: 27 de mar. 2021.

Recebido em: 26 de maio de 2021. Aceito em: 10 de setembro de 2021. Publicado em: 15 de dezembro de 2021. 